\title{
Poleward moving auroral arcs observed at the South Pole Station and the interpretation by field line resonances
}

\section{AUTHOR(S):}

Tanaka, Y. -M.; Ebihara, Y.; Saita, S.; Yoshikawa, A.; Obana, Y.; Weatherwax, A. T.

\section{CITATION:}

Tanaka, Y. -M. ... [et al]. Poleward moving auroral arcs observed at the South Pole Station and the interpretation by field line resonances. Journal of Geophysical Research: Space Physics 2012, 117(A9): A09305.

\section{ISSUE DATE:}

2012-09

URL:

http://hdl.handle.net/2433/193715

RIGHT:

(C)2012. American Geophysical Union. 


\title{
Poleward moving auroral arcs observed at the South Pole Station and the interpretation by field line resonances
}

\author{
Y.-M. Tanaka, ${ }^{1}$ Y. Ebihara, ${ }^{2}$ S. Saita ${ }^{3}$ A. Yoshikawa, ${ }^{4}$ Y. Obana, ${ }^{5}$ and A. T. Weatherwax ${ }^{6}$ \\ Received 2 May 2012; revised 12 July 2012; accepted 23 July 2012; published 8 September 2012.
}

[1] We investigate the characteristics of poleward moving auroral arcs (PMAAs) observed with the all-sky monochromatic imager at the South Pole Station $\left(74.3^{\circ} \mathrm{CGLAT}\right)$ in the interval 08:00-11:00 MLT on July 8, 2004. During this period, Pc 5 geomagnetic pulsations are also observed as well as quasi-stationary auroral patches (QSAPs), which keep their forms, luminosities, and locations for up to several hours. It is demonstrated that the PMAAs, Pc 5 pulsations in the north-south component, and oscillations in the drift of the QSAPs in the east-west direction have similar dominant periods and are well correlated with each other. The oscillatory ionospheric plasma drifts accompanying the PMAAs are extracted from the horizontal motion of the QSAPs and are found to propagate poleward with the PMAAs. The phase relations of the PMAAs and Pc 5 pulsations in the northward component with respect to the westward drift velocity of the QSAPs are close to anti-phase and in-phase, respectively. To examine whether these phenomena can be interpreted by field line resonances (FLRs), we perform a numerical simulation using a horizontally two-dimensional model that consists of the auroral acceleration region and the ionosphere with time-evolution conductivity. The results indicate that the observed data can be well explained by the FLR model with realistic physical parameters, except for the phase relation of the PMAAs with respect to the Pc 5 pulsations and the QSAPs.

Citation: Tanaka, Y.-M., Y. Ebihara, S. Saita, A. Yoshikawa, Y. Obana, and A. T. Weatherwax (2012), Poleward moving auroral arcs observed at the South Pole Station and the interpretation by field line resonances, J. Geophys. Res., 117, A09305, doi:10.1029/2012JA017899.

\section{Introduction}

[2] Poleward moving auroral forms (PMAFs) observed in the high-latitude ionosphere at around $75^{\circ}$ magnetic latitude (MLAT) on the dayside around 9-15 magnetic local time (MLT) are a manifestation of the interaction between the solar wind and the magnetosphere. PMAFs are characterized by a lifetime of 2-10 $\mathrm{min}$, a recurrence period of 3-15 $\mathrm{min}$, and a velocity of the poleward motion of less than $1.5 \mathrm{~km} / \mathrm{sec}$ [cf. Sandholt et al., 1990]. They are generally related to dayside reconnection and flux transfer events (FTEs). The occurrence frequency of PMAFs strongly depends on the solar

\footnotetext{
${ }^{1}$ National Institute of Polar Research, Tokyo, Japan.

${ }^{2}$ Research Institute for Sustainable Humanosphere, Kyoto University, Kyoto, Japan.

${ }^{3}$ Transdisciplinary Research Integration Center, Research Organization of Information and Systems, Tokyo, Japan.

${ }^{4}$ Department of Earth and Planetary Sciences, Kyushu University, Fukuoka, Japan.

${ }^{5}$ Department of Engineering Science, Osaka Electro-Communication University, Osaka, Japan.

${ }^{6}$ Department of Physics, Siena College, Latham, New York, USA.

Corresponding author: Y.-M. Tanaka, National Institute of Polar Research, 10-3 Midori-cho, Tachikawa, Tokyo 190-8518, Japan. (ytanaka@nipr.ac.jp)
}

wind parameters, in particular, $B_{z}$ and $B_{y}$ of the interplanetary magnetic field (IMF); PMAFs occur most frequently for IMF $B_{z}<0$ conditions but can also occur for $B_{z}>0$ conditions [Fasel, 1995; Drury et al., 2003]. A positive or negative $B_{y}$ enhances the observation of PMAFs in the prenoon or postnoon sectors in the Northern Hemisphere, respectively, and the $B_{y}$ dependence of PMAFs is antisymmetric in the Southern Hemisphere [Karlson et al., 1996; Sandholt et al., 1993; Drury et al., 2003].

[3] Quasiperiodic PMAFs correlated with ULF pulsations are occasionally related to field line resonances (FLRs) [Tamao, 1964; Southwood, 1974; Chen and Hasegawa, 1974; Milan et al., 1999a, 1999b, 2001; Kozlovsky and Kangas, 2002]. Milan et al. [1999a, 2001] examined PMAFs colocated with the convection reversal boundary in the postnoon sector and showed that the meridian scan data of PMAFs have the characteristics of FLRs, such as wave-like oscillations with a similar dominant frequency to the geomagnetic pulsations, occasional harmonic oscillations, and a $180^{\circ}$ phase change across the latitude of maximum emission intensity. Kozlovsky and Kangas [2002] investigated PMAFs observed equatorward of the convection reversal (i.e., on closed field lines) at 10:00-13:00 MLT using data from the all-sky camera and European Incoherent Scatter (EISCAT) VHF radar. They found that the spectra of the eastward plasma flow measured by the radar show clear peaks corresponding to the eigenfrequency of the FLR oscillations and suggested 
that the PMAFs are a result of interference between the eigenmode toroidal oscillations on different $L$ shells. In order to distinguish this type of event from the former-stated PMAFs, we refer to them as poleward moving auroral arcs (PMAAs), according to Kozlovsky and Kangas [2002]. In this paper, we define PMAAs as occurring in the closed field lines and associated with FLRs, whereas PMAFs occur on or in the vicinity of the open-close boundary mainly due to dayside reconnection.

[4] Even in the region far from the dayside cusp, PMAAs have been detected, for example, in the auroral zone in the nighttime [Samson et al., 1991, 1996]. Samson et al. [1996] demonstrated that meridian scans of all-sky images obtained in the nighttime auroral region show poleward moving discrete arcs and very clear ULF oscillations with the dominant frequency expected from the FLRs. Furthermore, other than the optical aurora, Pc 5 pulsations observed over a wide range of MLT by the STARE radar have often shown poleward moving structures in the backscatter echo and the FLRrelated spatial structures in the amplitude and phase of the east-west (E-W) plasma velocity [Walker et al., 1979; Walker and Greenwald, 1981; Poulter, 1982].

[5] Another aurora phenomenon closely related to ULF geomagnetic pulsations is oscillations in the drift of auroral patches or diffuse aurora [Oguti et al., 1987; Yamamoto et al., 1988]. The motion of auroral patches observed with all-sky TV imagers provides information on the twodimensional (2-D) distribution of the plasma convection. Oguti et al. [1987] examined spatial distribution of drifts of non-pulsating auroral patches in the evening sector and found that the auroral patches oscillate primarily in the E-W direction associated with concurrent magnetic pulsations and the oscillations of the patches are consistent with the electrostatic electric field accompanied by the pulsations.

[6] Recently, Ebihara et al. [2007] reported quasistationary auroral patches (QSAPs) observed at the South Pole Station $\left(-74.3^{\circ} \mathrm{CGLAT}\right)$ on the dayside at 09:00 14:00 MLT, which keep their form, location, and luminosity for up to several hours. They suggested that the QSAPs were generated in the central plasma sheet where the field lines are closed, because the QSAPs were observed at $557.7 \mathrm{~nm}$ equatorward of a longitudinally elongated arc detected at $630.0 \mathrm{~nm}$ at $78-79^{\circ} \mathrm{CGLAT}$, which is probably associated with the low-latitude boundary layer (LLBL) or the cleft region. Furthermore, the QSAPs showed periodic fluctuations of their drift velocity in the E-W direction and the fluctuations were well correlated with Pc 5 pulsations observed in the north-south (N-S) component. The relationship between the drift velocity of QSAPs, corresponding to the ionospheric electric field, and Pc 5 pulsations observed on the ground can be explained by the ionospheric current controlled by Ohm's law.

[7] This paper follows up the research of Ebihara et al. [2007]. We newly analyze PMAAs (that were not reported by Ebihara et al. [2007]) detected simultaneously with the QSAPs and Pc 5 pulsations in the same period analyzed by Ebihara et al. [2007]. The advantage of this study is that the QSAPs appeared simultaneously with the PMAAs for several hours and thus the spatial distribution of the ionospheric drift velocity associated with the PMAAs can be deduced from the horizontal motion of the QSAPs. In addition, we carry out a numerical simulation to examine whether these three phenomena, PMAAs, QSAPs, and Pc 5 pulsations, can be interpreted by the FLR mechanism.

\section{Data Set and Conditions During the Events}

[8] The data used in this paper are almost the same as those used by Ebihara et al. [2007]. We analyzed data recorded with the all-sky imager (ASI) and the fluxgate magnetometer at the South Pole Station (SPA) during the interval 11:00-17:00 UT, corresponding to $\sim 07: 30$ 13:30 MLT $($ MLT $\sim$ UT $-3.5 \mathrm{~h}$ at SPA), on July 8, 2004. In addition to these data, we analyzed magnetic data from Iqaluit (IQA), which is a station located close to the geomagnetic conjugate of SPA in the Northern Hemisphere. The ASI consists of a $180^{\circ}$ field-of-view lens ( $f=6 \mathrm{~mm}$, $\mathrm{F}=1.4$ ), a back-illuminated air-cooled CCD camera with a resolution of $512 \times 512$ pixels, and an automated filter changer with 557.7-nm and 630.0-nm monochromatic filters. The images at $557.7 \mathrm{~nm}$ were recorded with an exposure time of $8 \mathrm{~s}$ every $32 \mathrm{~s}$ during the period we analyzed. The absolute luminosities were calibrated using the integrating sphere at the National Institute of Polar Research, Japan.

[9] According to Ebihara et al. [2007], the solar wind and geomagnetic conditions were very quiet during this interval. The solar wind speed detected by the ACE satellite was about $310-340 \mathrm{~km} / \mathrm{s}$. The IMF $B_{z}$ was stably positive except for short periods around 14:20 and 15:00-15:30 UT. $K_{P}$ and $\mathrm{AE}$ indices were $0+$ to $1-$ and below 110 , respectively.

\section{Observational Results}

[10] Figure 1 shows the 557.7-nm images taken at SPA in the interval 12:14:56-12:25:42 UT as examples of PMAAs and QSAPs. The images were mapped to $110 \mathrm{~km}$ altitude. In this figure the PMAAs passed across the zenith at about $12: 17: 05,12: 21: 23$, and 12:25:42 UT from magnetic north to south (i.e., from low latitude to high latitude). Stable auroral patches can be seen on the magnetic north side of the images. The arrows in the images indicate the drift velocity of the auroral patches calculated from two consecutive images by minimum mean square error (MMSE) analysis [Ebihara et al., 2007]. In this paper we identified the auroral patches by a visual scan and manually determined the position of the scanning area for the MMSE analysis, which is different from the method used by Ebihara et al. [2007], who fixed the scanning area. We set the scanning area and the kernel area for the MMSE to $75 \mathrm{~km} \times 75 \mathrm{~km}$ and $37.5 \mathrm{~km} \times 37.5 \mathrm{~km}$, respectively [see Ebihara et al., 2007]. It appears that the QSAPs oscillate primarily in the magnetic E-W direction in correlation with the passage of the PMAAs.

[11] Figure 2 shows the keogram of $557.7 \mathrm{~nm}$ intensity in the magnetic N-S direction and the magnetic field observed with the fluxgate magnetometer at SPA in the interval 11:00-17:00 UT. The keogram was made from images mapped to $110 \mathrm{~km}$ altitude and its vertical axis represents the distance from the zenith. The quasiperiodic intensifications seen in the keogram correspond to the PMAAs. The intensifications due to the PMAAs can be clearly seen in the interval 11:30-14:00 UT, where Pc 5 pulsations occurred predominantly in the $\mathrm{H}$ and $\mathrm{Z}$ components. The bright auroral patches reached the zenith around 14:00 UT and moved southward and also westward (not shown here). After 

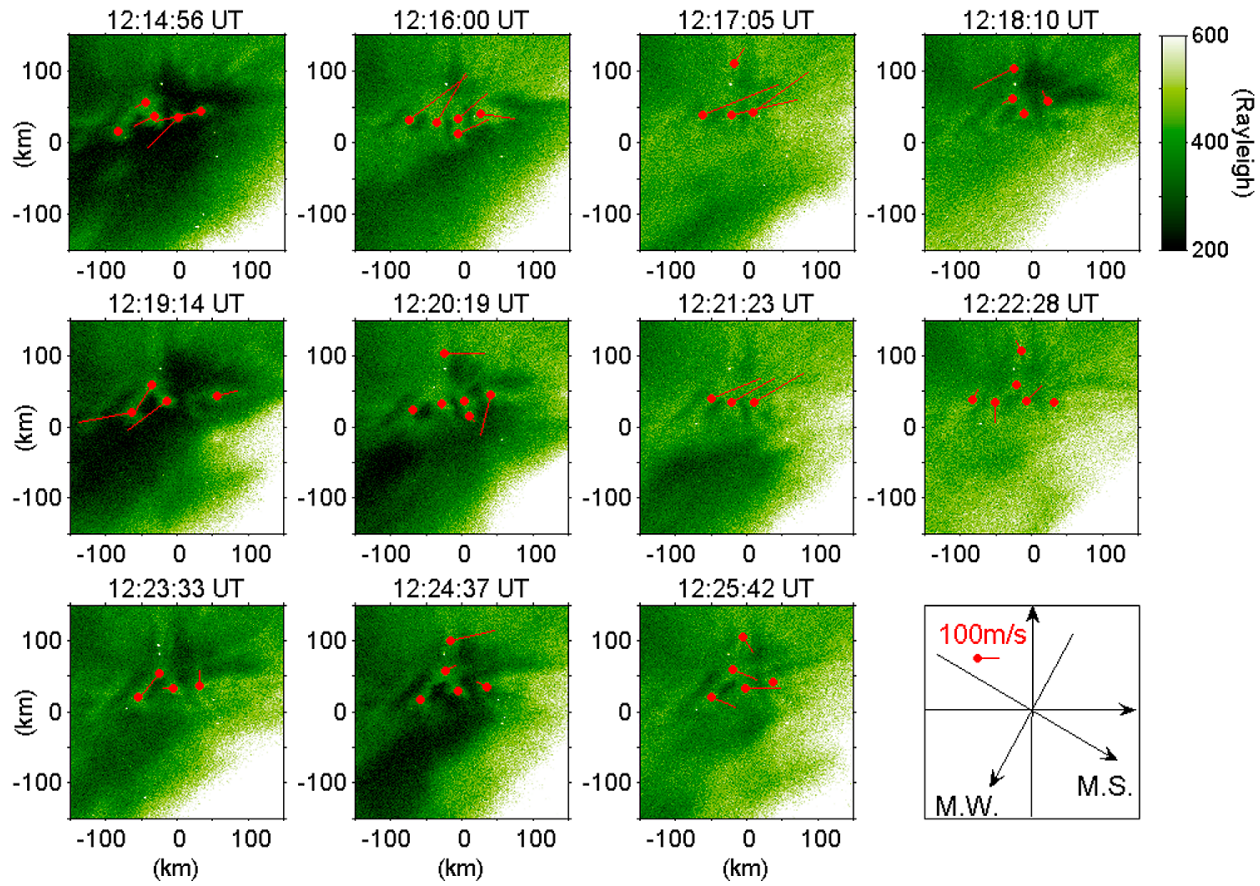

Figure 1. Auroral images at $557.7 \mathrm{~nm}$ taken at SPA in the interval 12:14:56-12:25:42 UT. The images were mapped to $110 \mathrm{~km}$ altitude and the top and right of the images correspond to the geographic north and east, respectively. The arrows in the images show the drift velocity of the selected auroral patches calculated from two consecutive images by MMSE analysis.

15:30 UT, the PMAAs could not be identified and the periods of the Pc 5 pulsations were longer than before 15:00 UT.

[12] It should be noted that in this paper the magnetic north is defined so as to be perpendicular to the PMAAs, that is, $25^{\circ} \mathrm{W}$ in geographic coordinates. The angle is similar to the declination at SPA, $-29^{\circ}$, calculated by the IGRF (International Geomagnetic Reference Field) model. The magnetic $\mathrm{N}-\mathrm{S}$ direction $\left(25^{\circ} \mathrm{W}\right.$ in geographic coordinates) is a rough estimation, because the PMAAs detected in this study were broad bands, as seen in Figure 1.
[13] We here explain the coordinate system used in this study. The origin is placed at SPA and the $x$ axis and $y$ axis are directed geomagnetically westward and southward, respectively. This coordinate system is also adopted for the numerical simulation in section 5 .

[14] Figure 3 shows an expanded view of Figure 2 in the interval 11:50-12:30 UT. The keogram in the magnetic E-W direction was added to Figure $3 \mathrm{~b}$. In order to highlight the PMAAs, the running average of the keogram over about 672 s (21 data points) was subtracted from the keogram in Figure 2. It can be confirmed that the auroral arcs

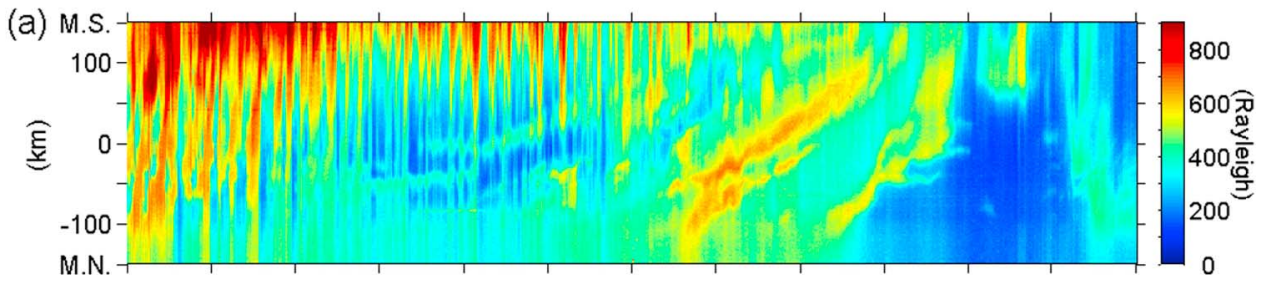

(b)

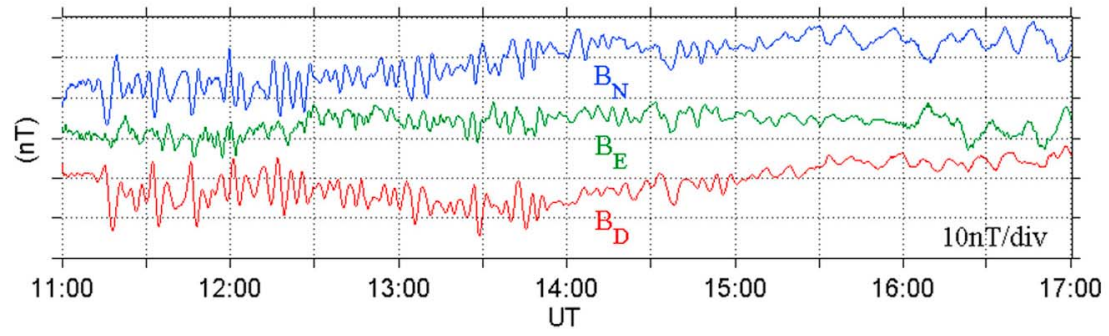

Figure 2. (a) Keogram along the magnetic meridian derived from auroral 557.7-nm images in the interval 11:00-17:00 UT. (b) Magnetic field measured with the fluxgate magnetometer at SPA. 

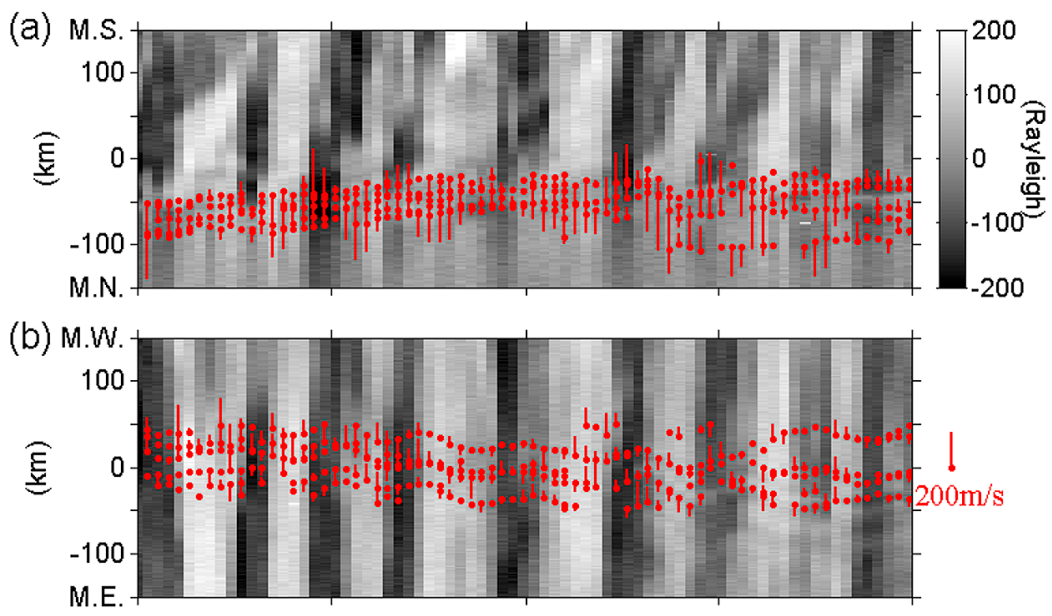

(c)

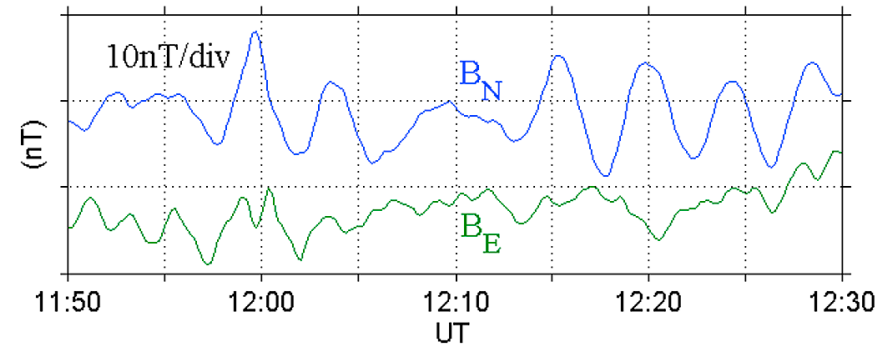

Figure 3. (a) N-S keogram of the 557.7-nm emission in the interval 11:50-12:30 UT. The running mean has been subtracted from the keogram. Note that the length of the arrows in the panel shows the E-W drift velocity of QSAPs. The solid circles exhibit the y coordinates of the QSAPs location. (b) E-W keogram of the 557.7-nm emission with the arrows indicating the N-S drift velocity of the QSAPs. The solid circles show the $\mathrm{x}$ coordinates of the QSAPs location. (c) Magnetic field in the N-S and E-W components.

propagated southward (poleward). The propagation velocities of the PMAAs observed in this interval are between 1 and $3 \mathrm{~km} / \mathrm{sec}$. The solid circles in the keograms exhibit the $y$ coordinates of the locations of the selected QSAPs events for the N-S keogram (Figure 3a) and the $\mathrm{x}$ coordinates for the E-W keogram (Figure 3b). The vertical arrows show the drift velocity of the QSAPs, which indicate the E-W component for the N-S keogram and the $\mathrm{N}-\mathrm{S}$ component for the E-W keogram. The upward arrows correspond to the westward drift in Figure $3 \mathrm{a}$ and the southward drift in Figure 3b. It is clearly evident that there is a one-to-one correspondence between the PMAAs, the Pc 5 pulsations in the N-S component $\left(\mathrm{B}_{\mathrm{N}}\right)$, and the oscillations in the E-W drift velocity of the QSAPs. It appears that these three phenomena are oscillating with similar periods and specific phase relations. On the other hand, there are no apparent relationships of the N-S drift velocity of the QSAPs (Figure $3 b$ ) and the magnetic field in the E-W component $\left(\mathrm{B}_{\mathrm{E}}\right.$ in Figure 3c) to the PMAAs.

[15] In order to investigate the latitudinal phase structure of the oscillations in the drift of the QSAPs, the averaged westward drift velocities of the QSAPs located at low latitudes $(-120 \mathrm{~km} \leq \mathrm{y}<-30 \mathrm{~km})$, around the zenith $(-30 \mathrm{~km} \leq$ $\mathrm{y}<30 \mathrm{~km})$, and at high latitude $(30 \mathrm{~km} \leq \mathrm{y}<120 \mathrm{~km})$ are separately presented in Figure 4. The QSAPs located within $-50 \mathrm{~km} \leq \mathrm{x} \leq 50 \mathrm{~km}$ were used for averaging. The lack of data in some intervals means that no QSAPs were identified in the intervals within the specified y-range. This figure indicates that the oscillations in the E-W drift of the QSAPs at high latitudes tend to lag behind those at low latitudes, in particular, in the interval 12:30-14:30 UT. The phase difference is ambiguous after 15:00 UT, because the number of the identified QSAPs was small.

[16] Figure 5 illustrates a relationship between the intensity of PMAAs $\left(\mathrm{I}_{5577}\right)$, the magnetic field in the N-S component, and the E-W drift velocity of the QSAPs in the interval 12:50-13:20 UT. $\mathrm{I}_{5577}$ shows the intensity of the keogram averaged over $y$ from $-30 \mathrm{~km}$ to $30 \mathrm{~km}$. $\mathrm{V}_{\mathrm{W}}$ is the averaged westward drift velocity of the QSAPs located at $-30 \mathrm{~km} \leq$ $\mathrm{y}<30 \mathrm{~km}$. This figure indicates that the phase relation between $V_{W}$ and $B_{N}$ is close to in-phase and $I_{5577}$ is nearly anti-phase with respect to $\mathrm{V}_{\mathrm{W}}$ and $\mathrm{B}_{\mathrm{N}}$. The dominant periods calculated by the spectral analysis are very similar to each other, i.e., 302, 299, and $299 \mathrm{~s}$ for $\mathrm{B}_{\mathrm{N}}, \mathrm{V}_{\mathrm{W}}$, and $\mathrm{I}_{5577}$, respectively. The correlation coefficient and the phase difference are -0.74 and $-8^{\circ}$ between $\mathrm{I}_{5577}$ and $\mathrm{V}_{\mathrm{W}}$ and 0.93 and $-31^{\circ}$ between $B_{N}$ and $V_{W}$, where the negative value of the phase difference means that $\mathrm{I}_{5577}$ and $\mathrm{B}_{\mathrm{N}}$ lag behind $\mathrm{V}_{\mathrm{W}}$. A similar phase relationship was obtained at 12:00-12:30 UT, shown in Figure 3. Since there were few QSAPs located around the zenith $(-30 \mathrm{~km} \leq \mathrm{y}<30 \mathrm{~km})$ in this interval, $\mathrm{V}_{\mathrm{W}}$ was calculated for $-120 \mathrm{~km} \leq \mathrm{y}<-30 \mathrm{~km}$. For the interval 12:00-12:30 UT, the dominant periods are 302, 293, and $293 \mathrm{~s}$ for $\mathrm{B}_{\mathrm{N}}, \mathrm{V}_{\mathrm{W}}$, and $\mathrm{I}_{5577}$, and the correlation coefficient and the phase difference are -0.76 and $-27^{\circ}$ between $\mathrm{I}_{5577}$ and $\mathrm{V}_{\mathrm{W}}$ and 0.90 and $-40^{\circ}$ between $\mathrm{B}_{\mathrm{N}}$ and $\mathrm{V}_{\mathrm{W}}$. If we use 

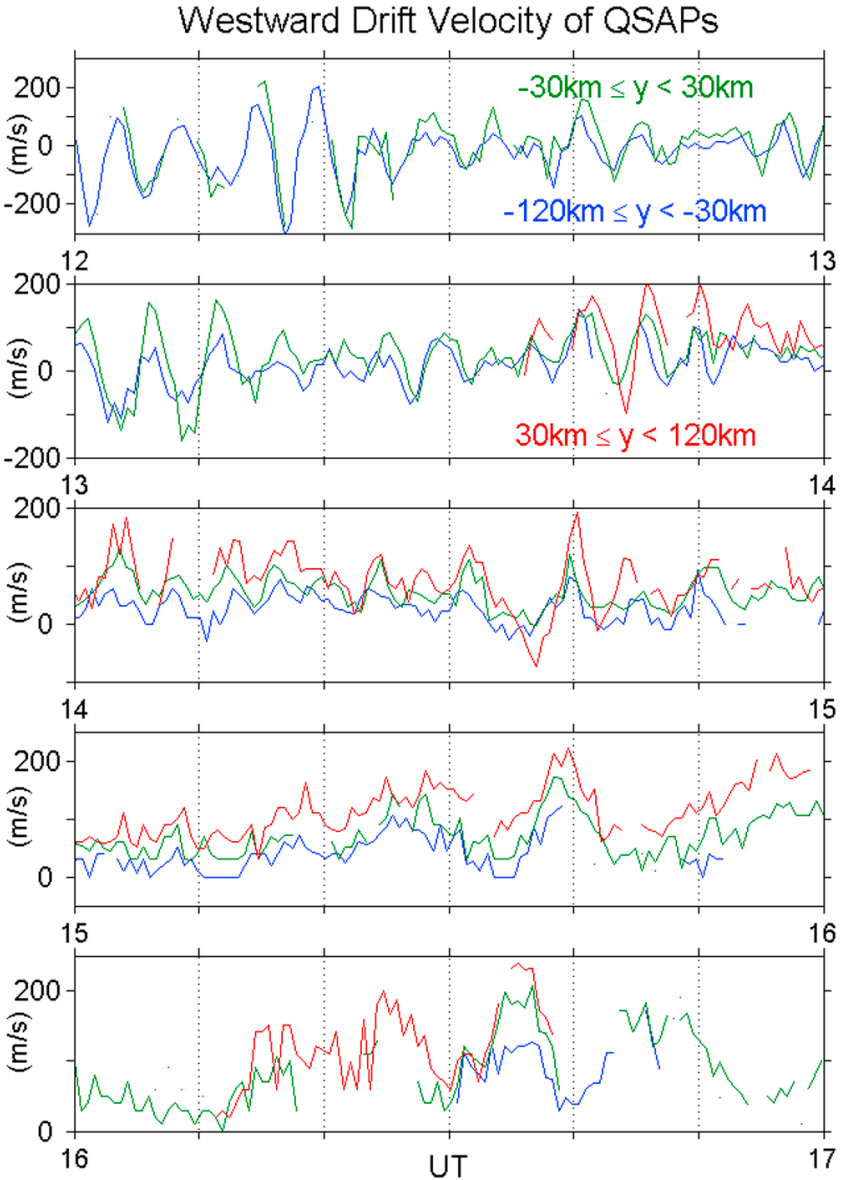

Figure 4. Latitudinal dependence of the westward drift velocity of the QSAPs. The blue, green, and red lines show the averaged velocities of the QSAPs in the areas $-120 \mathrm{~km} \leq \mathrm{y}<-30 \mathrm{~km},-30 \mathrm{~km} \leq \mathrm{y}<30 \mathrm{~km}$, and $30 \mathrm{~km} \leq \mathrm{y}<120 \mathrm{~km}$, respectively. The QSAPs located within $-50 \mathrm{~km} \leq \mathrm{x} \leq 50 \mathrm{~km}$ were used for averaging.

$\mathrm{V}_{\mathrm{W}}$ around the zenith as the reference for the phase difference, the phase difference is closer to $0^{\circ}$ because $V_{W}$ around the zenith tends to lag behind that at low latitude, as shown in Figure 4.

[17] Figure 6 shows the magnetic field observed in the interval 11:00-14:00 UT at Iqaluit (IQA), which is close to the geomagnetic conjugate point of SPA in the Northern Hemisphere, and at SPA. It was confirmed that Pc 5 pulsations were also observed at IQA and their waveform is quite similar to that at SPA. While the amplitude in $\mathrm{B}_{\mathrm{N}}$ and $\mathrm{B}_{\mathrm{D}}$ (downward) was greater at SPA than at IQA, $\mathrm{B}_{\mathrm{E}}$ was slightly greater at IQA than at SPA. The good correlation of the Pc 5 pulsations between SPA and IQA supports the standing field-line oscillations.

\section{Summary of Observational Results}

[18] The observational results are summarized as follows; [19] 1. PMAAs, QSAPs, and Pc 5 pulsations were simultaneously observed at SPA at 11:30-14:30 UT (08:0011:00 MLT) on July 8, 2004. The quasiperiodic PMAAs, the oscillations in the E-W drift velocity of the QSAPs, and

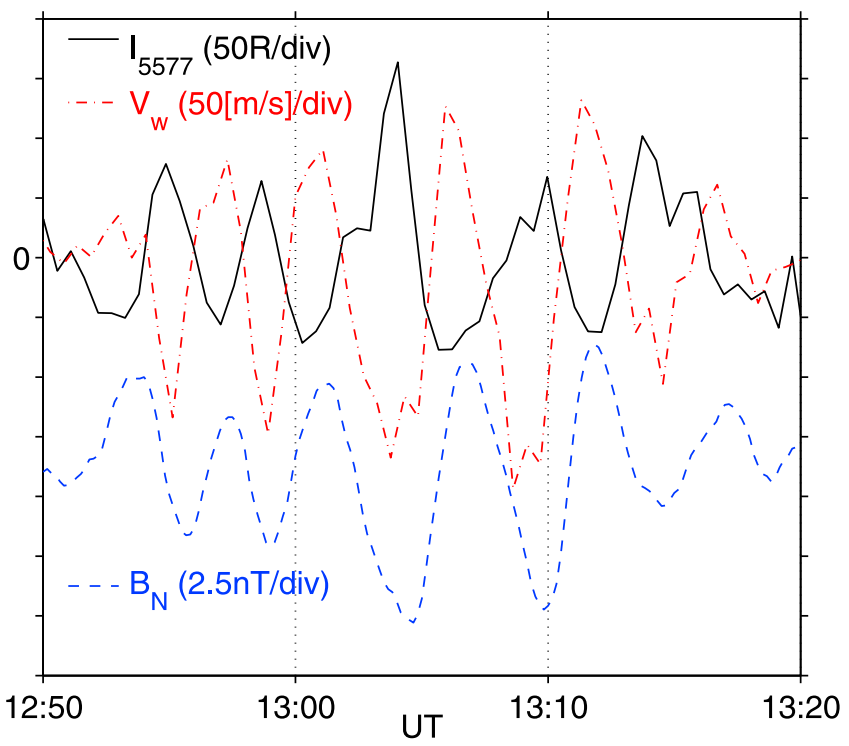

Figure 5. Relationship among the 557.7-nm intensity $\left(\mathrm{I}_{5577}\right)$ derived from the N-S keogram, drift velocity in the E-W direction of the QSAPs $\left(\mathrm{V}_{\mathrm{w}}\right)$, and magnetic variation in the N-S component $\left(\mathrm{B}_{\mathrm{N}}\right)$ in the interval 12:50 13:20 UT. $I_{5577}$ and $V_{w}$ were averaged in the region $-30 \mathrm{~km} \leq \mathrm{y}<30 \mathrm{~km}$, i.e., around zenith. The intensification of $\mathrm{I}_{5577}$ corresponds to the passage of the PMAAs through the zenith.

the Pc 5 pulsations in the N-S component correlated well with each other and had similar periods.

[20] 2. PMAAs were clear and the period of the Pc 5 pulsations is shorter before 14:30 UT (11:00 MLT), whereas the PMAAs were not identified and the Pc 5 pulsations have a longer period after 15:30 UT (12:00 MLT).

[21] 3. The oscillations in the westward velocity of the QSAPs $\left(\mathrm{V}_{\mathrm{W}}\right)$ at high latitudes lag behind those at low

(a) IQA

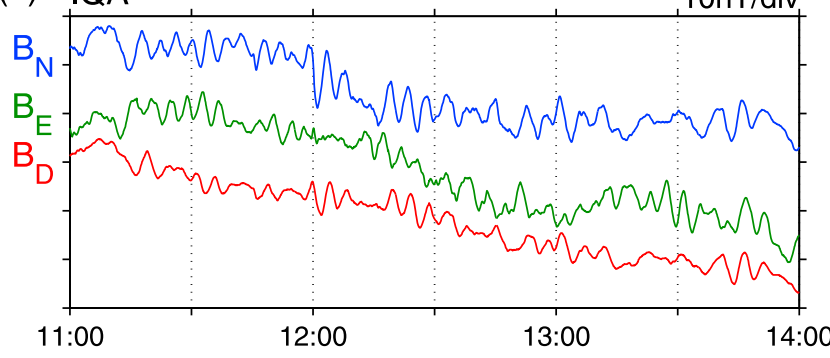

(b) SPA 10nT/div

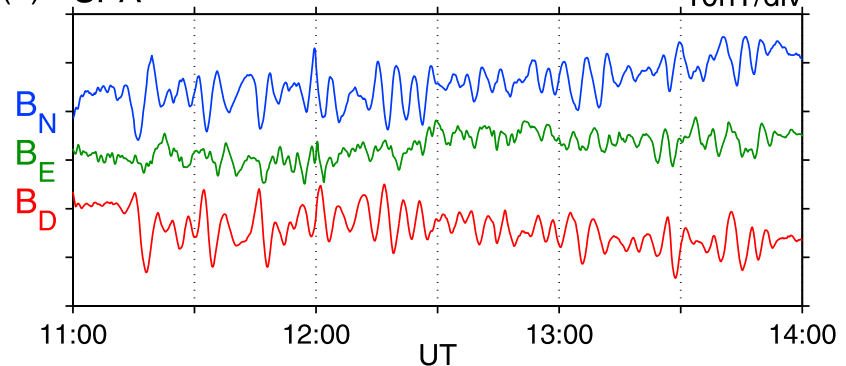

Figure 6. Magnetic variations observed in the interval 11:00-14:00 at (a) IQA and (b) SPA. 
latitudes. This lag indicates a poleward propagation of the oscillations of the QSAPs.

[22] 4. $\mathrm{V}_{\mathrm{W}}$ around the zenith was close to in-phase with respect to the northward magnetic variation $\left(\mathrm{B}_{\mathrm{N}}\right)$ and antiphase with respect to the luminosity variation due to the PMAAs around the zenith $\left(\mathrm{I}_{5577}\right)$. The phase differences are about $-10^{\circ}$ between $\mathrm{I}_{5577}$ and $\mathrm{V}_{\mathrm{W}}$ and about $-30^{\circ}$ between $\mathrm{B}_{\mathrm{N}}$ and $\mathrm{V}_{\mathrm{W}}$.

[23] 5. Coherent Pc 5 pulsations were also observed at IQA, which is located close to the magnetic conjugate of SPA in the Northern Hemisphere.

[24] In item 1, the good correlation between the PMAAs (or PMAFs) and Pc 5 pulsations has already been reported in many papers. Furthermore, the relationship between the oscillations in the drift of the auroral patches or diffuse aurora and Pc 5 pulsations has also been analyzed in detail [Oguti et al., 1987; Yamamoto et al., 1988; Ebihara et al., 2007]. This analysis showed that the auroral patches oscillate primarily in the E-W direction and the oscillations in the drift are consistent with the ionospheric electric field associated with ULF pulsations observed in the N-S component on the ground, which is consistent with our results. Oguti et al. [1987] further clarified that the oscillations in the E-W drift of non-pulsating auroral patches in the evening sector propagate poleward, associated with Pc 5 pulsations. Item 3 agrees with this previous result.

[25] The events analyzed by Yamamoto et al. [1988] are similar to those in this paper, although they were of a diffuse aurora, including a pulsating aurora, observed in the auroral zone in the dawn sector (around 04:30-07:30 MLT). They showed that the activation region of aurora quasiperiodically propagates toward the northwest, corresponding to the PMAAs, synchronized with Pc 5 pulsations. They also found that oscillations in the eastward drift of the auroral patches are synchronized with Pc 5 pulsations. Our observations have for the first time shown the relationship between these three phenomena (PMAAs, Pc 5 pulsations, and auroral patches) at very high latitude (74.3 CGLAT) in the interval 08:00-11:00 MLT.

[26] As Ebihara et al. [2007] have already shown, the field lines where the QSAPs were observed were closed and connected to the central plasma sheet, because the QSAPS were observed at $557.7 \mathrm{~nm}$ equatorward of a longitudinally elongated arc detected at $630.0 \mathrm{~nm}$, which is related to the LLBL or the cleft region. The coherent Pc 5 pulsations observed both at SPA and IQA (item 5) support the magnetic field lines from the SPA and IQA being closed and forming standing waves. In addition to these facts, the solar wind speed was slow and the IMF $B_{z}$ was northward during this period. Farrugia et al. [2000] have reported that in such northward IMF conditions, ULF pulsations associated with the FLRs were observed simultaneously with oscillations in aurora luminosity at $0900-1000 \mathrm{MLT}$ and $70-80^{\circ}$ magnetic latitudes. Therefore, it is concluded that the FLR model is more suitable for the generation of the PMAAs shown in this paper than the dayside reconnection model.

\section{Numerical Simulation and Discussion}

[27] In this section, we perform a numerical simulation to examine whether the observed results can be explained by the FLR model with realistic values of the physical parameters.
The simulation is based on the magnetosphere-ionosphere coupling model introduced by Janhunen and Huuskonen [1993], which includes the auroral acceleration region (AAR) and variable ionospheric conductivity. Our model, however, does not include the magnetosphere and consists of only the AAR and the ionosphere. The model is horizontally two-dimensional (2-D) except for the electron density distribution in the ionosphere, which is calculated in three dimensions. We adopted a Cartesian coordinate system with the origin at SPA, the $y$ axis geomagnetically southward (i.e., poleward), the $x$ axis westward, and the $\mathrm{z}$ axis vertically upward. The ambient magnetic field lines are assumed to be parallel to the $\mathrm{z}$ axis.

[28] We assumed that the Knight relation is satisfied for the field-aligned current (FAC) in the AAR [Knight, 1973] and the ionospheric current is controlled by Ohm's law under the thin-shell assumption of the ionosphere. We solve the current continuity equations on the boundary between the magnetosphere and the AAR, and the boundary between the $\mathrm{AAR}$ and the ionosphere:

$$
\begin{gathered}
j_{z, M}=K \Delta_{\|} \Phi \\
=\Sigma_{P} \nabla_{\perp}^{2} \Phi_{I}+\nabla_{\perp} \Sigma_{P} \cdot \nabla_{\perp} \Phi_{I}-\hat{\mathbf{e}}_{z} \cdot\left(\nabla_{\perp} \Sigma_{H} \times \nabla_{\perp} \Phi_{I}\right),
\end{gathered}
$$

where $j_{z, M}$ is the FAC in the magnetosphere, $K$ and $\Delta_{\|} \Phi$ are the Lyons-Evans-Lundin constant and the parallel potential drop in the AAR, respectively [Lyons et al., 1979; Fridman and Lemaire, 1980]. The right-hand side of (2) comes from the convergence of the ionospheric current, and $\Sigma_{P}, \Sigma_{H}$, and $\Phi_{I}$ are the height-integrated Pedersen and Hall conductivities and the electric potentials on the ionosphere, respectively. If $j_{z, M}, K, \Sigma_{P}$, and $\Sigma_{H}$ are given, we can solve (1) for $\Delta_{\|} \Phi$ and (2) for $\Phi_{I} \cdot j_{z, M}$ is given as the source associated with the FLRs, as described later. We solved (2) for $\Phi_{I}$ by the finite difference method. We adopted the alternating direction implicit (ADI) algorithm with the boundary conditions of Dirichlet $\left(\Phi_{I}=0\right)$ in the $y$ direction and Nuemann in the $x$ direction.

[29] $\Sigma_{P}$ and $\Sigma_{H}$ are time-dependent and were obtained from

$$
\sum_{P, H}=\int F_{P, H}(z) n(x, y, z, t) d z
$$

where $n(x, y, z, t)$ is the electron number density and $F_{P, H}(z)$ is the conductivity per unit electron density. $F_{P, H}(z)$ is a function of only $\mathrm{z}$ and is obtained from the number densities of the neutral gas $\left(n_{N_{2}}, n_{\mathrm{O}_{2}}, n_{O}\right)$ and ions $\left(n_{\mathrm{O}^{+}}, n_{\mathrm{O}_{2}}, n_{\mathrm{NO}^{+}}\right)$, the temperature of the ion, electrons, and neutrals $\left(T_{i}, T_{e}, T_{n}\right)$, and the ambient magnetic field strength $\left(B_{0}\right)$. These parameters were derived from the MSISE90, IRI 2001, and IGRF models [Hedin, 1991; Bilitza, 2001; International Association of Geomagnetism and Aeronomy, Division V, Working Group VMOD: Geomagnetic Field Modeling, 2005].

[30] The distribution of $n$ is calculated from the evolution equation of $n$ shown by

$$
\frac{\partial n}{\partial t}+\nabla_{\perp} \cdot\left(n \mathbf{v}_{\perp}\right)=q_{0}+q_{Q S A P S}+q_{P}-\alpha n^{2}
$$


where $\mathbf{v}_{\perp}, q_{0}, q_{Q S A P S}, q_{P}$, and $\alpha$ are the ionospheric plasma velocity, the background ion production rate, the ion production rate associated with the QSAPs, the ion production rate due to the electron precipitation, and the effective recombination coefficient. Since $\mathbf{v}_{\perp}$ is the $\mathrm{E} \times \mathrm{B}$ drift, it is calculated from $\Phi_{I}$ and $B_{0}$. Equation (4) was solved for $n$ by the forward Euler method.

[31] $q_{P}$ was calculated according to Rees [1989], i.e.,

$$
q_{P}=\pi \int\left[\frac{\rho(z) \lambda(z, E) E}{\Delta \varepsilon_{\text {ion }} R(E)} f\left(E, \Delta_{/ /} \Phi\right)\right] d E
$$

where $\rho(z)$ is the atmospheric mass density, $\lambda(z, E)$ is the energy dissipation function, $E$ is the energy, $\Delta \varepsilon_{i o n}$ is the energy for producing a pair of ion, $R(E)$ is the range of the incident electrons with energy $E$, and $f\left(E, \Delta_{\|} \Phi\right)$ is the differential directional number flux of precipitating electrons. We assumed the isotropic pitch angle distribution for the incident electrons. Detailed values of these parameters are given in the appendix of Tanaka et al. [2011].

[32] In the AAR, $f$ was assumed to be the accelerated Maxwellian distribution given by

$$
f=\frac{n_{M}}{\sqrt{2 \pi^{3} m_{e} k_{B}^{3} T_{M}^{3}}} E \exp \left(-\frac{E-e \Delta_{\|} \Phi}{k_{B} T_{M}}\right)\left(E \geq e \Delta_{\|} \Phi\right)
$$

where $k_{B}, m_{e}, e, n_{M}$, and $T_{M}$ are the Boltzman constant, the electron mass, the electric charge, the source plasma density, and the magnetospheric electron temperature. $n_{M}$ and $T_{M}$ were assumed to be constant in this paper, so $q_{P}$ are dependent on $\Delta_{\|} \Phi$ only.

[33] According to Janhunen and Huuskonen [1993], $q_{0}$ is expressed by

$$
q_{0}=\alpha\left\{\Sigma_{H, 0} n_{0} \exp \left[-\left(\frac{z-z_{p}}{w}\right)^{2}\right]\right\}^{2},
$$

where we assumed the height profile of the electron density for the quiet condition, determined by $\Sigma_{H, 0}, n_{0}, z_{p}$, and $w$. We set $z_{p}$ to $124 \mathrm{~km}$ and $w$ to $15 \mathrm{~km}$. $n_{0}$ was set so that $q_{0}(z)$ produces a uniform background Hall conductivity of $\Sigma_{H}=$ $\Sigma_{H, 0}$ in the case when $q_{P}$ and $q_{Q S A P S}$ vanish. Since the electron density profile is fixed when $\Sigma_{H, 0}$ is set, the background Pederson conductivity is also obtained and is close to $\Sigma_{H, 0}$.

[34] $q_{Q S A P S}$ was also calculated in a similar way to $q_{0}$, but $\Sigma_{H, Q S A P S}(x, y, t)$ is non-uniform instead of a scalar $\Sigma_{H, 0}$ in (7). Moreover, $\Sigma_{H, Q S A P s}$ was assumed to change so as to satisfy the equation

$$
\frac{\partial \Sigma_{H, Q S A P S}}{\partial t}+\nabla \cdot\left(\Sigma_{H, Q S A P S} \mathbf{v}_{\perp}\right)=0 .
$$

Equation (8) indicates that the QSAPs move with the ionospheric plasma and the total amount of the source of the QSAPs $\left(q_{Q S A P S}\right)$ is constant, because $q_{Q S A P s}$ is proportional to $\Sigma_{H, Q S A P s}$.

[35] $j_{z, M}$ on the top of the AAR was associated with the FLRs. The magnetic perturbations, $b_{x}$, of the toroidal mode oscillations due to the FLRs are often approximated by the driven damped harmonic oscillation as shown below:

$$
\ddot{b_{x}}+2 \gamma \dot{b}_{x}+\omega_{R}^{2} b_{x}=\omega_{R}^{2} c \cdot \sin \left(\omega_{D} t\right)
$$

where $\omega_{R}(y), \omega_{D}, \gamma$, and $c$ are the undamped angular frequency corresponding to the resonant frequency, the driving frequency, the dumping ratio, and a constant associated with the amplitude of the fast mode waves [Gough and Orr, 1984; Menk et al., 1994]. It was assumed that $\omega_{R}$ depends on $y$ only and thus $b_{x}$ is a function of $y$ and uniform in the $x$ direction. The general solution of (9) is known to be

$$
b_{x}=a e^{-\gamma t} \sin \left(\sqrt{\omega_{R}^{2}-\gamma^{2}} t+\epsilon\right)+A \sin \left(\omega_{D} t-\delta\right),
$$

where $a$ and $\epsilon$ are constants and $A$ and $\delta$ are given by

$$
\begin{gathered}
A=\frac{c \omega_{R}^{2}}{\sqrt{\left(\omega_{R}^{2}-\omega_{D}^{2}\right)^{2}+4 \gamma^{2} \omega_{D}^{2}}}, \\
\delta=\tan ^{-1}\left(\frac{2 \gamma \omega_{D}}{\omega_{R}^{2}-\omega_{D}^{2}}\right)
\end{gathered}
$$

The first and second terms of the right-hand side of (10) are the transient solution and the steady state solution, respectively. The first term is damped with a damping constant $\gamma$. The PMAAs due to the first term were discussed by Kozlovsky and Kangas [2002]. In this paper we assumed a monochromatic source and consider only the second term of (10). $j_{z, M}$ was obtained from Ampère's law $\left(j_{z, M}=-\mu_{0}^{-1} \partial b_{x} / \partial y\right)$.

[36] For simplicity, we assumed that the FLRs have already been formed at the beginning of the calculation and $A$ and $\delta$ do not change temporally. This assumption is not practical, because reflected waves from the ionosphere change with the temporal variation of the conductivities.

[37] The latitudinal distribution of $\omega_{R}\left(=2 \pi / T_{R}\right)$ was calculated using the approximation of the fundamental toroidal eigenperiod discussed by Vellante and Förster [2006, equation (8)], assuming the Tsyganenko 96 magnetic field model [Tsyganenko, 1995] and an inverse power law radial density variation along the field lines, $\rho_{M}=\rho_{M, e q}\left(r / r_{e q}\right)^{-3}$, where $\rho_{M}$ and $r$ are the ion mass density and radial distance from the center of the earth. We found that the equatorial ion mass density, $\rho_{M, e q}$, on the field line threading SPA is $0.24 \mathrm{amu} / \mathrm{cc}$, which matches the resonance frequency at SPA $\left(\omega_{R}\right.$ at $\left.y=0\right)$ with the observed Pc 5 frequency. The radial profile of $\rho_{M, e q}$ was assumed to be equal to that of the equatorial electron number density, $n_{M, e q}$. The equatorial electron density was derived from Carpenter and Anderson [1992, equation (6)], where the second term of the equation was ignored because it causes an increase of the electron density with $L$ at very large $L$. We multiplied the radial density profile by a constant to fit $\rho_{M, e q}$ at SPA to $0.24 \mathrm{amu} / \mathrm{cc}$. The calculated resonant period, $T_{R}$, is presented in Figure 7. $\omega_{D}$ was assumed to be the same as $\omega_{R}$ at $y=0$.

[38] The magnetic field observed on the ground can be obtained from the ionospheric current. The total ionospheric 


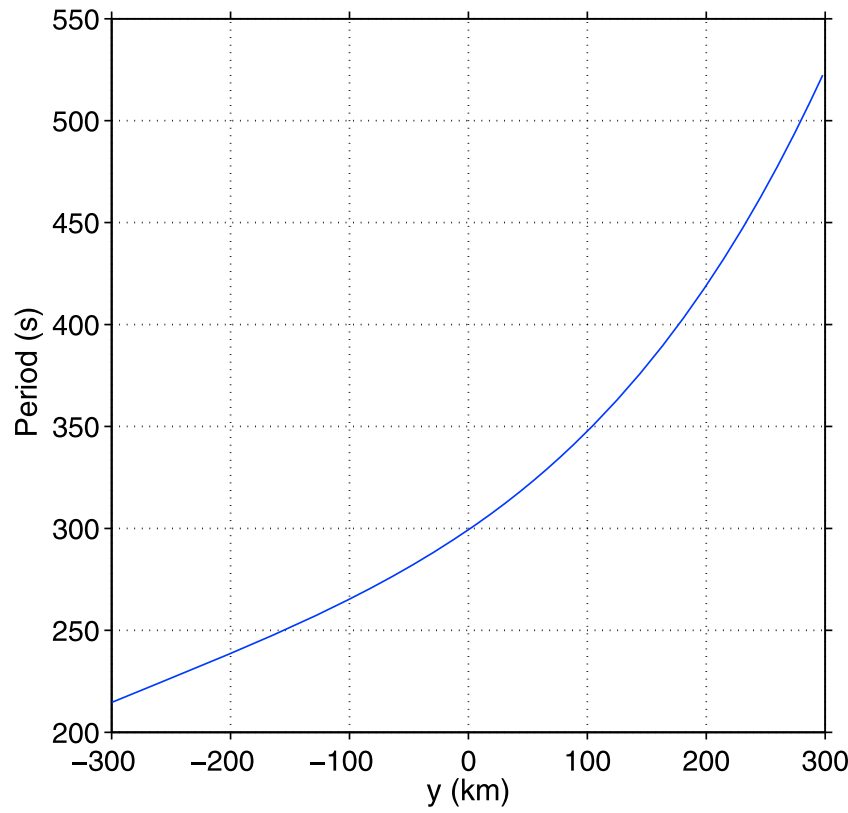

Figure 7. Latitudinal distribution of the FLR frequency assumed for the numerical simulation.

current was first separated into the divergence-free and the curl-free vector fields. Since the ground magnetic field generated from the curl-free ionospheric current is canceled by that from FACs, the ground magnetic field was calculated from the divergence-free current by Biot-Savart's law [e.g., Raeder et al., 2001, equations (22)-(29)]. It was assumed
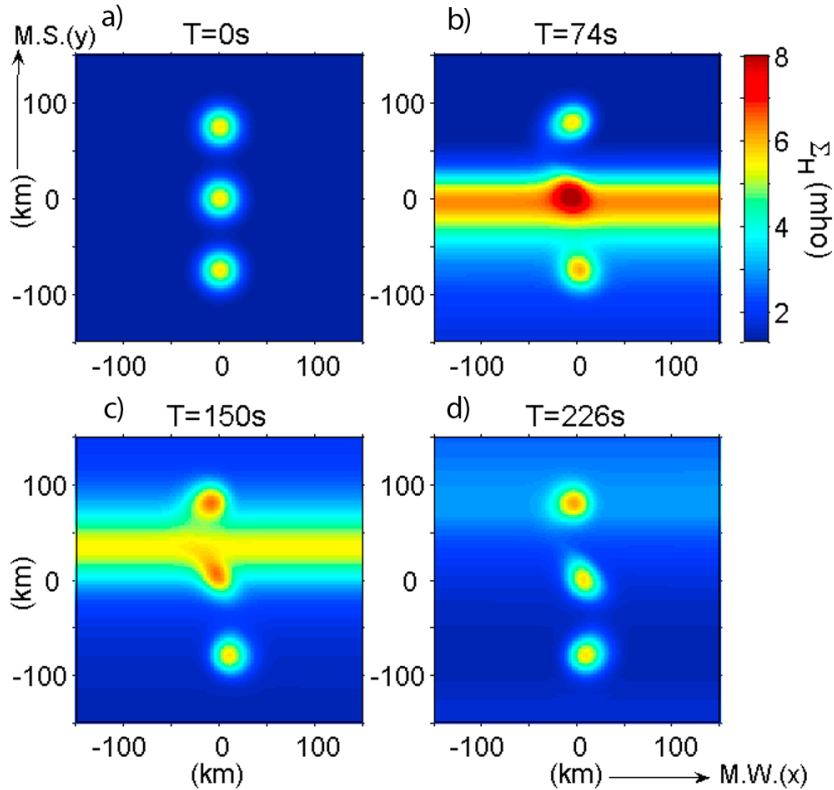

Figure 8. Height-integrated Hall conductivity $\left(\Sigma_{H}\right)$ calculated from the simulation. The top and right of each panel correspond to the south and west, respectively.

that the ionospheric current flows at $110 \mathrm{~km}$ altitude and the solid Earth is a perfect conductor.

[39] The parameters used in the calculation are summarized in Table 1 . We adjusted the parameters $c, K$, and $\Sigma_{H, 0}$ so as to match the simulation results with the observed data $\left(\mathrm{V}_{\mathrm{W}}, \mathrm{B}_{\mathrm{N}}\right.$, and $\left.\mathrm{I}_{5577}\right)$.

Table 1. Simulation Parameters

\begin{tabular}{|c|c|c|}
\hline Symbol & Value & Explanation \\
\hline$K$ & $2.0 \times 10^{-10} \mathrm{mho} \mathrm{m}^{-2}$ & $\begin{array}{l}K \text { is generally assumed to be between } 10^{-8} \text { and } 10^{-10} \mathrm{mho} \mathrm{m}^{-2} \\
\quad \text { [Olsson et al., 1996]. It satisfies the equation } K \approx e^{2} n_{M} / \sqrt{2 \pi m_{e} k_{B} T_{M}} \text {. }\end{array}$ \\
\hline$F_{P, H}(z)$ & 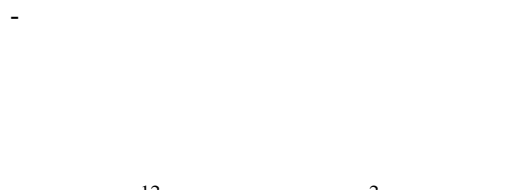 & $\begin{array}{l}F_{P, H}(z) \text { are calculated based on Richmond }[1995] . \\
F_{P, H}(z) \text { need } n_{N_{2}}, n_{\mathrm{O}_{2}}, n_{\mathrm{O}}, n_{\mathrm{O}^{+}}, n_{\mathrm{O}^{+}}, n_{\mathrm{NO}^{+}}, T_{i}, T_{e}, T_{n} \text {, and } B_{0}, \\
\text { calculated from MSISE90, IRI2000, IGRF models } \\
\text { [Hedin, 1991; Bilitza, 2001; International Association } \\
\text { of Geomagnetism and Aeronomy, Division V, Working } \\
\text { Group VMOD: Geomagnetic Field Modeling, 2005]. }\end{array}$ \\
\hline$\alpha(z)$ & $\begin{array}{l}4.30 \times 10^{-12} \exp \left(-2.42 \times 10^{-2} \mathrm{z}\right)+8.16 \\
\quad \times 10^{6} \exp (-0.524 \mathrm{z})\left[\mathrm{m}^{3} \mathrm{~s}^{-1}\right](z \text { is in } \mathrm{km})\end{array}$ & Gledhill, $[1986]$ \\
\hline$\rho(z)$ & - & $\rho(z)$ was obtained from MSISE90 model [Hedin, 1991]. \\
\hline$\Delta \epsilon_{i o n}$ & $35.5 \mathrm{eV}$ & Rees [1989] \\
\hline$\lambda(z, E)$ & - & Semeter and Kamalabadi [2005, Table 1] \\
\hline$R(E)$ & $\begin{array}{l}4.30 \times 10^{-6}+5.36 \times 10^{-5} E^{1.67}\left[\mathrm{~kg} \mathrm{~m}^{-2}\right] \\
(E \text { is in } \mathrm{keV})\end{array}$ & Rees [1989] \\
\hline$n_{M}$ & $0.24 \times 10^{6} \mathrm{~m}^{-3}$ & $\begin{array}{l}\text { It was assumed that } n_{M} \text { is equal to } n_{M, e q} \text { and the ions } \\
\text { consist of protons only. }\end{array}$ \\
\hline$k_{B} T_{M}$ & $1 \mathrm{keV}$ & Thermal energy of source electrons \\
\hline$\Sigma_{H, 0}$ & $1.3 \mathrm{mho}$ & Background Hall conductivity \\
\hline$\Sigma_{H, Q S A P s}(t=0 s)$ & - & Gaussian distribution with a maximum of 4 mho \\
\hline$\gamma$ & $0.1 \omega_{R}$ & Damping ratio \\
\hline$T_{D}\left(=2 \pi / \omega_{D}\right)$ & $300 \mathrm{~s}$ & Period of driving waves \\
\hline$\Delta t$ & $2 \mathrm{~s}$ & Time step \\
\hline$x_{\min }-x_{\max }$ & $-300-300 \mathrm{~km}$ & Spatial range in $x\left(=y_{\min }-y_{\max }\right)$ \\
\hline$z_{\min }-z_{\max }$ & $80-200 \mathrm{~km}$ & Altitude range \\
\hline & $2 \mathrm{~km}$ & Grid spacing in $x\left(=\Delta_{y}\right)$ \\
\hline & $4 \mathrm{~km}$ & Grid spacing in $z$ \\
\hline$E_{\min }-E_{\max }$ & $0.3-20 \mathrm{keV}$ & Energy range \\
\hline$N_{E}$ & 30 & $\begin{array}{l}\text { Number of energy grid. The energy range is divided } \\
\text { by } N_{E} \text { logarithmically. }\end{array}$ \\
\hline
\end{tabular}



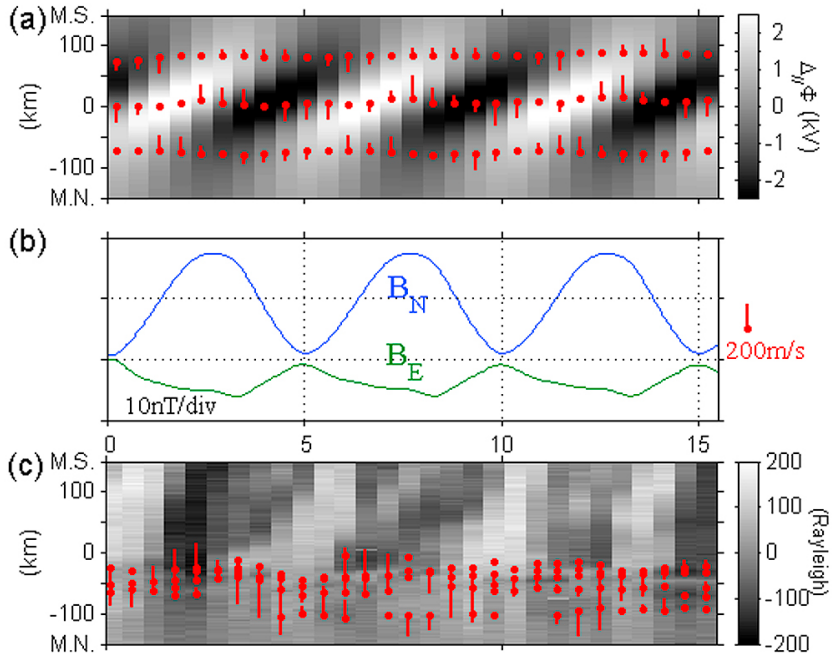

(d)

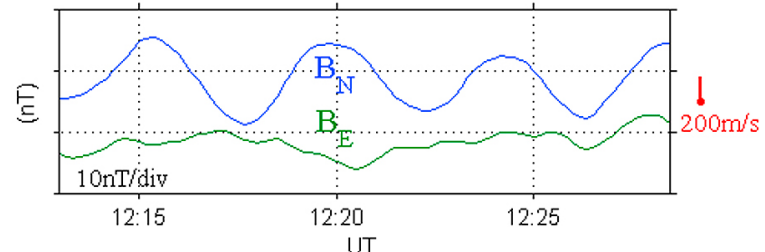

Figure 9. (a) N-S keogram of the field-aligned potential drop with the E-W drift velocity of the auroral patches and (b) magnetic field on the ground obtained from the numerical simulation. (c) N-S keogram of the 557.7-nm intensity with the E-W drift velocity of the QSAPs and (d) magnetic field on the ground observed in the interval 12:13-12:29 UT.

[40] Figure 8 shows the temporal variation of $\Sigma_{H}$ calculated from the simulation. As seen in Figure 8a, it was assumed that the QSAPs at $t=0 \mathrm{~s}$ were located at $(x, y)=$ $(0,-75),(0,0)$, and $(0,75)$ in $\mathrm{km}$ and the shape of the QSAPs is the Gaussian distribution. The E-W elongated enhanced $\Sigma_{H}$ in Figures $8 \mathrm{~b}-8 \mathrm{~d}$ that propagates poleward corresponds to the PMAAs. The QSAPs oscillate dominantly in the E-W direction as the PMAAs pass over the QSAPs. It can be found that the QSAPs move eastward on the south side of the arc and westward on the north side.

[41] Here, we attempt to reproduce the observed data from the simulation results. The results are presented in Figures 9a and $9 \mathrm{~b}$, together with the data observed at 12:13-12:29 UT in Figures 9c and 9d. Figure 9a shows the N-S keogram of the field-aligned potential drop $\left(\Delta_{\|} \Phi\right)$ with the E-W drift velocity of the assumed patches obtained from the simulation. The positive $\Delta_{\|} \Phi$ indicates an upward FAC and electron precipitation, corresponding to the auroral emission. For a comparison with the observation, these data were sampled every $32 \mathrm{~s}$ from the simulation results. The calculated N-S and E-W components of the ground magnetic field are presented in Figure 9b. The simulated data are quite similar to the observed data. It is clear that the three phenomena have a high correlation coefficient and almost the same dominant frequencies. The amplitude of $\mathrm{B}_{\mathrm{N}}$ and $\mathrm{V}_{\mathrm{W}}$ are about $8 \mathrm{nT}$ and $200 \mathrm{~m} / \mathrm{s}$, respectively, which are comparable to the observed values. $\Delta_{\|} \Phi$ is about $3 \mathrm{kV}$ at maximum and is large enough to excite the 557.7-nm emission. The observed in-phase relation between $\mathrm{B}_{\mathrm{N}}$ and $\mathrm{V}_{\mathrm{w}}$ is also reproduced well by the simulation.

[42] On the other hand, it is difficult to explain the antiphase relation of the PMAAs with respect to $B_{N}$ and $V_{W}$, because it is expected from the simulation that the PMAAs precede $B_{N}$ and $V_{W}$ by $90^{\circ}$. The discrepancy between the observation and simulation may be attributed to the weak and broad auroral arcs. The PMAAs analyzed in this paper were much weaker and latitudinally broader than typical PMAAs [e.g., Milan et al., 1999a, 2001]. The broad arcs are consistent with the relatively small latitudinal phase variation in Figure 4, which is smaller than that reported by Milan et al. [1999a, 2001], who showed a $180^{\circ}$ phase shift within $1^{\circ}$ latitude across the latitude of maximum emission intensity. The broad latitudinal wave structure of the arcs may cause difficulties in determining the phase relation between the auroral luminosity and the ionospheric flow.

[43] The attenuation of the PMAAs after 15:00 UT (item 5 of the observation summary) may also be explained by this model. By rewriting the current continuity equations (1) and (2), the field-aligned potential drop is appropriated by

$$
\Delta_{\|} \Phi=\frac{-1}{K} \nabla_{\perp} \cdot\left(\Sigma_{P} \mathbf{E}_{\perp, I}+\Sigma_{H} \hat{\mathbf{e}}_{z} \times \mathbf{E}_{\perp, I}\right) \approx-\frac{i k_{y}}{K} \Sigma_{P} E_{y, I},
$$

where $\mathbf{E}_{\perp, I}$ is the horizontal component of the ionospheric electric field and $k_{y}$ is the meridional wave number. It is deduced from the westward drift velocity in Figure 4 that $E_{y, I}$ associated with the Pc 5 pulsations after 14:00 UT is smaller by roughly half than that before 14:00 UT. This is also supported by the attenuation in the amplitude of the Pc5 pulsations after 14:00 UT (Figure 2b). Moreover, $k_{y}$ should be smaller after 15:00 UT than before 14:00 UT, because the dominant period of the Pc 5 pulsations is much longer after 15:00 UT ( $\sim 620 \mathrm{~s})$ than before 14:00 UT ( $\sim 330 \mathrm{~s})$ and thus the phase variation along the meridian is smaller. Therefore, it is reasonable to assume that the field-aligned potential drop after 15:00 UT is too small to generate the PMAAs.

\section{Conclusions}

[44] The PMAAs, the Pc 5 pulsations, and the oscillations in the drift of the QSAPs observed at SPA (74.3 CGLAT) in the interval 08:00-11:00 MLT showed good correlations, similar dominant periods, and a systematic phase difference between each other. They occurred during the northward IMF condition and in the closed field lines, because the QSAPs at $557.7 \mathrm{~nm}$ were located at lower latitudes than the LLBL or the cleft region and similar Pc 5 pulsations were observed at a geomagnetic conjugate station of SPA, IQA in the northern hemisphere. Hence, FLRs are the most probable generation mechanism of these three phenomena. The numerical simulation using 2-D models that consist of the AAR and the ionosphere clarified that the FLR model can reasonably explain most of the observed data, i.e., the amplitude of the Pc 5 pulsations in the N-S component $\left(B_{N}\right)$, the E-W drift velocity of the QSAPs $\left(V_{W}\right)$, the 557.7-nm emission corresponding to the field-aligned potential drop greater than $1 \mathrm{kV}$, and the in-phase relation between $\mathrm{B}_{\mathrm{N}}$ and $\mathrm{V}_{\mathrm{W}}$. Therefore, we conclude that the PMAAs, the Pc 5 pulsations, and the oscillations in the drift of the QSAPs shown in this paper are various aspects of the FLRs. On the 
other hand, the phase relation of the PMAAs with the other two phenomena remains a puzzle and will be explored in future research.

[45] Acknowledgments. The research presented here was partially supported by the National Science Foundation Office of Polar Programs through grants NSF-0638587 and ANT-0840158. We wish to thank Louis Lanzerotti and Andrew Gerrard at the New Jersey Institute for Technology for his support and guidance with regard to the South Pole Station fluxgate magnetometer observations. This work was partly supported by the IUGONET (Inter-university Upper atmosphere Global Observation NETwork) project (http://www.iugonet.org/) funded by the Ministry of Education, Culture, Sports, Science and Technology (MEXT), Japan. The production of this paper was supported by an NIPR publication subsidy. The Canadian Magnetic Observatory Network (CANMON), maintained and operated by the Geological Survey of Canada, provided the magnetic field data at Iqaluit (http://gsc.nrcan.gc.ca/geomag).

[46] Robert Lysak thanks the reviewers for their assistance in evaluating this paper.

\section{References}

Bilitza, D. (2001), International Reference Ionosphere 2000, Radio Sci., $36(2), 261-275$.

Carpenter, D. L., and R. R. Anderson (1992), An ISEE/whistler model of equatorial electron density in the magnetosphere, J. Geophys. Res., 97(A2), 1097-1108, doi:10.1029/91JA01548.

Chen, L., and A. Hasegawa (1974), A theory of long-period magnetic pulsations: 1. Steady state excitation of field line resonance, J. Geophys. Res., 79, 1024-1032.

Drury, E. E., S. B. Mende, H. U. Frey, and J. H. Doolittle (2003), Southern Hemisphere poleward moving auroral forms, J. Geophys. Res., 108(A3), 1114, doi:10.1029/2001JA007536.

Ebihara, Y., Y.-M. Tanaka, S. Takasaki, A. T. Weatherwax, and M. Taguchi (2007), Quasi-stationary auroral patches observed at the South Pole Station, J. Geophys. Res., 112, A01201, doi:10.1029/2006JA012087.

Farrugia, C. J., P. E. Sandholt, N. C. Maynard, W. J. Burke, J. D. Scudder, D. M. Ober, J. Moen, and C. T. Russell (2000), Pulsating midmorning auroral arcs, filamentation of a mixing region in a flank boundary layer, and ULF waves observed during a Polar-Svalbard conjunction, J. Geophys. Res., 105(A12), 27,531-27,553.

Fasel, G. J. (1995), Dayside poleward moving auroral forms: A statistical study, J. Geophys. Res., 100(A7), 11,891-11,905, doi:10.1029/ 95JA00854.

Fridman, M., and J. Lemaire (1980), Relationship between auroral electron fluxes and field aligned electric potential difference, J. Geophys. Res., 85 , 664-670.

Gledhill, J. A. (1986), The effective recombination coefficient of electrons in the ionosphere between 50 and $150 \mathrm{~km}$, Radio Sci., 21(3), 399-408.

Gough, H., and D. Orr (1984), The effect of damping on geomagnetic pulsation amplitude and phase at ground observatories, Planet. Space Sci., 32(5), 619-628.

Hedin, A. E. (1991), Extension of the MSIS thermosphere model into the middle and lower atmosphere, J. Geophys. Res., 96, 1159-1172.

International Association of Geomagnetism and Aeronomy, Division V, Working Group VMOD: Geomagnetic Field Modeling (2005), The 10th-Generation International Geomagnetic Reference Field, Geophys. J. Int., 161, 561-565.

Janhunen, P., and A. Huuskonen (1993), A numerical ionospheremagnetosphere coupling model with variable conductivities, J. Geophys. Res., 98(A6), 9519-9530, doi:10.1029/92JA02973.

Karlson, K. A., M. Oieroset, J. Moen, and P. E. Sandholt (1996), A statistical study of flux transfer event signatures in the dayside aurora: The IMF By-related prenoon-postnoon asymmetry, J. Geophys. Res., 101, $59-68$

Knight, S. (1973), Parallel electric fields, Planet. Space Sci., 21, 741-750.

Kozlovsky, A., and J. Kangas (2002), Motion and origin of noon highlatitude poleward moving auroral arcs on closed magnetic field lines, J. Geophys. Res., 107(A2), 1017, doi:10.1029/2001JA900145.

Lyons, L. R., D. S. Evans, and R. Lundin (1979), An observed relation between magnetic field aligned electric fields and downward electron energy fluxes in the vicinity of auroral forms, J. Geophys. Res., 84, $457-461$.
Menk, F. W., B. J. Fraser, C. L. Waters, C. W. S. Ziesolleck, Q. Feng, S. H. Lee, and P. W. McNabb (1994), Ground measurements of low latitude magnetospheric field line resonances, in Solar Wind Sources of Magnetospheric Ultra-Low-Frequency Waves, Geophys. Monogr. Ser. vol. 81, edited by M. J. Engebreston, K. Takahashi, and M. Scholer, pp. 299-310, AGU, Washington, D. C., doi:10.1029/GM081p0299.

Milan, S. E., T. K. Yeoman, M. Lester, J. Moen, and P. E. Sandholt (1999a), Post-noon two-minute period pulsating aurora and their relationship to the dayside convection pattern, Ann. Geophys., 17, 877-891.

Milan, S. E., M. Lester, S. W. H. Cowley, J. Moen, P. E. Sandholt, and C. J. Owen (1999b), Meridian-scanning photometer, coherent HF radar, and magnetometer observations of the cusp: A case study, Ann. Geophys., $17,159-172$.

Milan, S., N. Sato, M. Ejiri, and J. Moen (2001), Auroral forms and the field-aligned current structure associated with field line resonances, J. Geophys. Res., 106(A11), 25,825-25,833, doi:10.1029/2001JA900077.

Oguti, T., R. Nakamura, and T. Yamamoto (1987), Oscillations in drifts of auroral patches, J. Geomagn. Geoelectr., 39, 609-624.

Olsson, A., A. I. Eriksson, and P. Janhunen (1996), On the current-voltage relationship in auroral breakups and westwards-travelling surges, Ann. Geophys., 14, 1265-1273.

Poulter, E. M. (1982), Pc 5 micropulsation resonance regions observed with the STARE radar, J. Geophys. Res., 87, 8167-8173, doi:10.1029/ JA087iA10p08167.

Raeder, J., R. L. McPherron, L. A. Frank, S. Kokubun, G. Lu, T. Mukai, W. R. Paterson, J. B. Sigwarth, H. J. Singer, and J. A. Slavin (2001), Global simulation of the Geospace Environment Modeling substorm challenge event, J. Geophys. Res., 106(A1), 381-395.

Rees, M. H. (1989), Physics and Chemistry of the Upper Atmosphere, edited by J. T. Houghton, M. J. Rycroft, and A. J. Dessler, Cambridge Univ. Press, New York.

Richmond, A. D. (1995), Ionospheric electrodynamics, in Handbook of Atmospheric Electrodynamics, vol. 2, 249-290, CRC Press, Boca Raton, Fla

Samson, J. C., T. J. Hughes, F. Creutzberg, D. D. Wallis, R. A. Greenwald, and J. M. Ruohoniemi (1991), Observations of a detached, discrete arc in association with field line resonances, J. Geophys. Res., 96(A9), 15,683-15,695, doi:10.1029/91JA00796.

Samson, J. C., L. L. Cogger, and Q. Pao (1996), Observations of field line resonances, auroral arcs, and auroral vortex structures, J. Geophys. Res., 101(A8), 17,373-17,383, doi:10.1029/96JA01086.

Sandholt, P. E., M. Lockwood, T. Oguti, S. W. H. Cowley, K. S. C. Freeman, B. Lybekk, A. Egeland, and D. M. Willis (1990), Midday auroral breakup events and related energy and momentum transfer from the magnetosheath, J. Geophys. Res., 95, 1039-1060.

Sandholt, P. E., J. Moen, A. Rudland, D. Opsvik, W. F. Denig, and T. Hansen (1993), Auroral event sequences at the dayside polar cap boundary for positive and negative IMF $\mathrm{B}_{\mathrm{Y}}$, J. Geophys. Res., 98, 7737-7755.

Semeter, J., and F. Kamalabadi (2005), Determination of primary electron spectra from incoherent scatter radar measurements of the auroral E region, Radio Sci., 40, RS2006, doi:10.1029/2004RS003042.

Southwood, D. J. (1974), Some features of field line resonances in the magnetosphere, Planet. Space Sci., 22, 483-491.

Tamao, T. (1964), The structure of three-dimensional hydromagnetic waves in a uniform cold plasma, J. Geomagn. Geoelectr., 18, 89-114.

Tanaka, Y.-M., T. Aso, B. Gustavsson, K. Tanabe, Y. Ogawa, A. Kadokura, H. Miyaoka, T. Sergienko, U. Brändström, and I. Sandahl (2011), Feasibility study on generalized-aurora computed tomography, Ann. Geophys., 29, 551-562, doi:10.5194/angeo-29-551-2011.

Tsyganenko, N. A. (1995), Modeling the Earth's magnetospheric magnetic field confined within a realistic magnetopause, J. Geophys. Res., 100, $5599-5612$.

Vellante, M., and M. Förster (2006), Inference of the magnetospheric plasma mass density from field line resonances: A test using a plasmasphere model, J. Geophys. Res., 111, A11204, doi:10.1029/2005JA011588.

Walker, A. D. M., and R. A. Greenwald (1981), Statistics of occurrence of hydromagnetic oscillations in the Pc5 range observed by the STARE auroral radar, Planet. Space Sci., 29, 293-305.

Walker, A. D. M., R. A. Greenwald, W. F. Stuart, and C. A. Green (1979), STARE auroral radar observations of Pc5 geomagnetic pulsations, J. Geophys. Res., 84, 3373-3388.

Yamamoto, T., et al. (1988), Auroral activities and long-period geomagnetic pulsations: 1 Pc5 pulsations and concurrent auroras in the dawn sector, J. Geomagn. Geoelectr., 40, 553-569. 